\title{
Gilles Negrello, Léon Bloy critique
}

Ida Merello

\section{(2) OpenEdition}

\section{Journals}

\section{Edizione digitale}

URL: http://journals.openedition.org/studifrancesi/30646

DOI: 10.4000/studifrancesi.30646

ISSN: 2427-5856

\section{Editore}

Rosenberg \& Sellier

\section{Edizione cartacea}

Data di pubblicazione: 1 avril 2006

Paginazione: 186

ISSN: 0039-2944

\section{Notizia bibliografica digitale}

Ida Merello, «Gilles Negrello, Léon Bloy critique», Studi Francesi [Online], 148 (XLX | I) | 2006, online dal 30 novembre 2015, consultato il 21 avril 2021. URL: http://journals.openedition.org/studifrancesi/ 30646 ; DOI: https://doi.org/10.4000/studifrancesi.30646

\section{Questo documento è stato generato automaticamente il 21 avril 2021.}

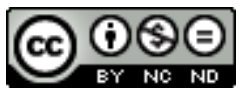

Studi Francesi è distribuita con Licenza Creative Commons Attribuzione - Non commerciale - Non opere derivate 4.0 Internazionale. 


\title{
Gilles Negrello, Léon Bloy critique
}

\author{
Ida Merello
}

\section{NOTIZIA}

GILLES NEGRELLO, Léon Bloy critique, Paris, Champion, 2005, pp. 470.

1 La critica letteraria di Léon Bloy ha sempre un po' scoraggiato l'approccio critico, dato il suo carattere parziale e appassionato, spesso pamphlettistico, l'atteggiamento ondivago, a seconda delle sedi di pubblicazione e delle reti di amicizie del momento, insomma, come confessa Negrello stesso, l'irregolarità e l'eterogeneità della produzione. Il lavoro dell'A. non si fa quindi illusioni sulle conclusioni, ma affronta coraggiosamente l'insieme del materiale, stabilendo per prima cosa uno spartiacque con il romanzo del Désespéré (1887). In una prima fase l'opera critica di Bloy, sparsa su pubblicazioni cattoliche di varia importanza (tra cui il quotidiano "L'Univers"), non ha carattere regolare. Diventa più continua a partire dalla collaborazione allo "Chat noir", così pubblica Propos d'un entrepreneur de démolitions (1884) e fonda "Le Pal", un pamphlet settimanale, per evitare i rifiuti dei vari giornali. Costretto rapidamente a chiudere, tenta di dare un seguito ai Propos, con Belluaires et Bouviers, senza riuscire a chiudere il libro: il progetto evolve a seconda delle diverse influenze, naturalista negli interventi sul "Gil Blas", simbolista sulla "Plume". L'A.osserva come Bloy appartenga a una generazione precedente a quella degli scrittori che animano i nuovi movimenti artistici e perciò sia incapace di apprezzare le idee più innovative. A poco a poco lo strumento critico diventa il mezzo per lo scrittore di trovare la sua collocazione nel panorama delle tendenze letterarie, risultando quindi sempre più secondario rispetto all'atto creativo. L'A. sottolinea l'importanza dell'amicizia con Huysmans per la rivalutazione di Flaubert, di Goncourt e di Zola e l'empatia che gli permette di apprezzare immediatamente un autore come Lautréamont, o Villiers de l'Isle-Adam. Mostra infine l'incidenza della delusione della pubblicazione di Là-bas (1891) da parte di Huysmans sul resto della produzione di Bloy, che dispera ormai di un rinnovamento letterario 
cattolico, rinuncia al sistema interpretativo che aveva iniziato con Belluaires et Bouviers e chiude pressoché completamente la sua attività di critica letteraria.

2 Il volume è accompagnato da una ricchissima bibliografia e da un indice cronologico delle opere di Bloy dal 1867 al 1894. 